\title{
SURVEY: PONDERAÇÕES ACERCA DE UMA IDEIA PARA REDUÇÃO DOS ÍNDICES DE PLÁGIO EM TRABALHOS ACADÊMICOS
}

\author{
Wendel Carlos de Souza ${ }^{1}$ \\ Anderson Luís Venâncio²
}

Resumo: O tema Plágio nos últimos anos vem sofrendo tratativas consideráveis por renomados pesquisadores, mesmo que estas, ainda sejam consideradas exploratórias, pois, levantam hipóteses e ainda não atuam com eficiência para minimizar estes altos índices de plágio. Visando a educação, a ciência e o presente cenário, esta pesquisa tem por conceito e finalidade o desenvolvimento de um Survey a ser respondido por discentes do ensino superior, visando futuramente quantificar e qualificar informações relevantes para maturação da ideia de melhoria e viabilização de treinamento destes discentes com foco na redução dos altos índices de plágio em trabalhos acadêmicos com interface nas normas regulamentadoras brasileiras, elevadas pela Associação Brasileira de Normas Técnicas, que tem por objetivo à regulamentação e padronização das informações para produção e execução de textos acadêmicos.

Palavras-chave: ABNT; Andragogia; SURVEY; Docência.

${ }^{1}$ Docência do Ensino Superior / Kroton Anhanguera SJC, Brasil. E-mail: wendel.souza@aedu.com.

${ }^{2}$ Reitoria da Universidade de Franca $/$ Universidade de Franca, Brasil. E-mail: anderson.venancio@anhanguera.com. 